This is a pre-print of the paper published in

Computers and Geotechnics, Volume 118, February 2020, 103329

https://doi.org/10.1016/j.compgeo.2019.103329

\title{
Non-orthogonal elastoplastic model for sand with dilatancy
}

\author{
Jingyu Liang ${ }^{1}$, Dechun $\mathrm{Lu}^{2}$,*, Xiuli $\mathrm{Du}^{3}$, Wei $\mathrm{Wu}^{4}$, Chao $\mathrm{Ma}^{5}$
}

\begin{abstract}
A non-orthogonal elastoplastic constitutive model for the sand with dilatancy is presented in the characteristic stress space. Dilatancy of sand is represented by the direction of plastic flow, which can be directly determined by applying the non-orthogonal plastic flow rule to an improved elliptic yield function. A new hardening parameter is developed to describe the contractive and dilative volume change during the shear process, which is coordinated with the non-orthogonal plastic flow direction. The combination of the non-orthogonal plastic flow rule and the proposed hardening parameter renders the proposed model with the ability to reasonably describe the stress-strain relationship of sand with dilatancy. The model performance is evaluated by comparing with the experimental data of sand under triaxial conditions.
\end{abstract}

Keywords: Sand; Dilatancy; Constitutive model; Non-orthogonal plastic flow rule; Hardening parameter; Characteristic stress

1 Ph.D. Candidate. Key Laboratory of Urban Security and Disaster Engineering of Ministry of Education, Beijing University of Technology, Beijing 100124, China. E-mail: liangjingyu@emials.bjut.edu.cn (J.Y. Liang).

2* Professor. Key Laboratory of Urban Security and Disaster Engineering of Ministry of Education, Beijing University of Technology, Beijing 100124, China (Corresponding author). E-mail: dechun@bjut.edu.cn (D.C. Lu).

3 Professor. Key Laboratory of Urban Security and Disaster Engineering of Ministry of Education, Beijing University of Technology, Beijing 100124, China. E-mail: duxiuli@bjut.edu.cn (X.L. Du).

4 Professor. Institute of Geotechnical Engineering, University of Natural Resources and Life Sciences, Vienna, 1180, Austria. E-mail: wei.wu@boku.ac.at (W. Wu).

5 Ph.D. Beijing Advanced Innovation Center for Future Urban Design, Beijing University of Civil Engineering and Architecture, Beijing 102616, China. Email: machao@bucea.edu.cn (C. Ma). 


\section{Introduction}

Dilatancy refers to the volume change observed in granular materials during shear deformations ${ }^{[1-4]}$. It is an essential property of sand. Loose sand tends to show negative dilatancy of volumetric contraction, while dense sand undergoes positive dilatancy ${ }^{[4,5]}$. One of the fundamental issues in modelling the mechanical behaviour of sand is to describe the dilatancy by the ratio of the plastic volumetric strain increment to the plastic shear strain increment ${ }^{[6,7]}$. The ratio can be expressed by the direction of the plastic flow ${ }^{[8,9]}$. Since the axis of the plastic strain increment is assumed to be coaxial with that of stress, the plastic flow direction can be determined by the plastic flow rule in the stress space ${ }^{[10-14]}$. The direction of the plastic strain increment is usually determined based on the orthogonal gradient of the plastic potential function. Obviously, this makes the plastic flow direction and its evolution rule inseparable from the plastic potential surface. However, an appropriate plastic potential function is difficult to be directly constructed based on experimental data, and some additional parameters may be required ${ }^{[15-17]}$. In fact, the purpose of constructing the plastic potential function is to produce the proper plastic flow direction. As an alternative, the plastic flow direction can also be directly achieved by applying the nonorthogonal plastic flow rule to the yield function ${ }^{[18-20]}$. The non-orthogonal plastic flow rule has been used to model the dilatancy behaviours of soil under triaxial compression conditions ${ }^{[20-23]}$. However, for three-dimensional (3D) stress conditions, the non-orthogonal plastic flow rule has not been well applied to simulate positive dilatancy ${ }^{[19]}$. How to use the non-orthogonal plastic flow rule to describe the negative/positive dilatancy of sand under $3 \mathrm{D}$ stress conditions and then establish a 3D non-orthogonal model for sand is worthy of further study.

Although the non-orthogonal plastic flow direction can be used to represent the stress-dilatancy relationship for sand, it does not mean that the shear responses of the sand with dilatancy have been totally captured. A proper hardening parameter is still needed in describing the contractive-dilative behaviour of sand. If hardening rule stems only from volume change, just as the models for normally consolidated clay ${ }^{[21,24-26]}$, once the critical state of zero incremental dilation is reached, the ultimate plastic deformation occurs and hardening stops ${ }^{[17]}$. Obviously, the plastic volumetric strain is not suitable for direct use as a hardening parameter to predict the dilative behaviour of sand. Therefore, the hardening parameter should be reconstructed. Several hardening parameters and hardening modulus have been proposed and used for modelling dilatancy behaviours of sand that is related to 
density and stress state ${ }^{[27-30]}$, anisotropy ${ }^{[31-33]}$ and even fabric evolution ${ }^{[34-36]}$. However, they are all formulated based on orthogonal plastic flow conditions. As a key point to reflect the dilatancy of sand, an appropriate hardening parameter should be coordinated with the plastic flow direction. That is, the hardening parameters derived for the orthogonal plastic flow rule cannot be directly introduced into a non-orthogonal model. Therefore, a hardening parameter should be reconstructed to match up with the non-orthogonal plastic flow direction.

In this paper, the non-orthogonal plastic flow rule is applied to capture the dilatancy behaviour of sand. The plastic flow direction under 3D stress conditions is directly determined by applying the non-orthogonal plastic flow rule to the elliptic yield function in the characteristic stress space. Furthermore, a hardening parameter for sand with dilatancy is constructed to match up with the nonorthogonal plastic flow direction. The capability of the proposed 3D model in modelling the shear response of sand with the negative and positive dilatancy is verified by predicting test results of sand.

\section{Framework of 3D non-orthogonal elastoplastic model in the $c_{i j}$ space}

Based on the elastoplastic theory, the total strain $\varepsilon_{i j}$ and its increment $\mathrm{d} \varepsilon_{i j}$ can be decomposed into the reversible elastic strain component and the irreversible plastic strain component:

$$
\varepsilon_{i j}=\varepsilon_{i j}^{\mathrm{e}}+\varepsilon_{i j}^{\mathrm{p}}, \quad \mathrm{d} \varepsilon_{i j}=\mathrm{d} \varepsilon_{i j}^{\mathrm{e}}+\mathrm{d} \varepsilon_{i j}^{\mathrm{p}}
$$

For the plastic strain increment, the non-orthogonal plastic flow rule proposed by Lu et al. ${ }^{[19,}$ ${ }^{37]}$ is adopted and can be expressed as:

$$
\mathrm{d} \varepsilon_{i j}^{\mathrm{p}}=\Lambda \cdot m_{i j}=\Lambda \cdot \frac{\partial^{\mu} f}{\partial S_{k l}{ }^{\mu}} \frac{\partial S_{k l}}{\partial \sigma_{i j}}
$$

where $\Lambda$ is the plastic multiplier, and $m_{i j}(i, j=1,2,3)$ is the plastic flow direction. $S_{k l}(k, l=1,2,3)$ is stress invariant that constructs the yield function and is associated with $\sigma_{i j}$. The non-orthogonal plastic flow rule is illustrated in Fig. 1: first determine the non-orthogonal gradient $\partial^{\mu} f / \partial S_{k l}{ }^{\mu}$ of the yield function by the fractional derivative in the $S_{k l}$ coordinate system, and then transform the non-orthogonal gradient in the $S_{k l}$ coordinate system to the $\sigma_{i j}$ coordinate system by the coordinate transformation $\partial S_{k l} / \partial \sigma_{i j}$. The non-orthogonal plastic flow rule in tensor form is the kernel for determining the general expression of plastic strain increment, which is essential for the model implementation ${ }^{[26,38,39]}$. The plastic flow direction $m_{i j}$ is non-orthogonal to the yield surface, which 


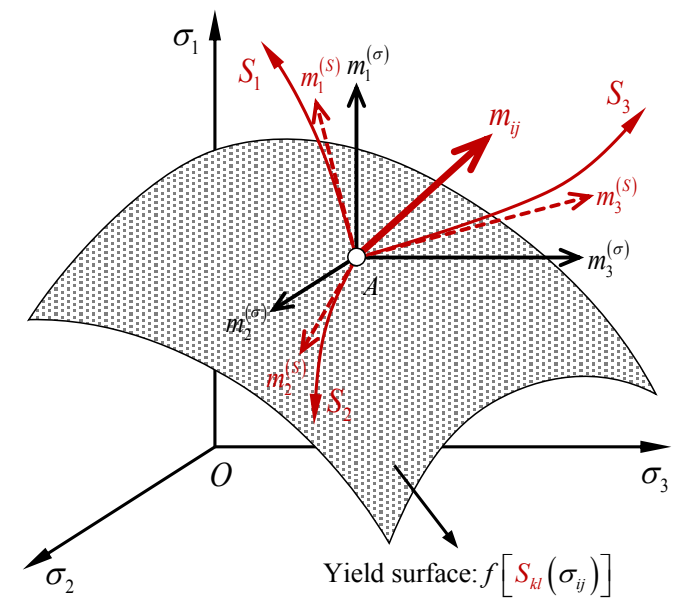

Fig. 1 Schematic diagram of the non-orthogonal plastic flow rule.

In order to make the proposed non-orthogonal model be born with the potential to reflect the $3 \mathrm{D}$ properties of soil, the concept of the characteristic stress $c_{i j}$ is introduced ${ }^{[19,40]}$. More details on the definition of the $c_{i j}$ and the corresponding variables are provided in Appendix A. The general form of the yield function in the $c_{i j}$ space can thus be expressed as:

$$
f=f\left[c_{i j}, H\left(\varepsilon_{r s}^{\mathrm{p}}\right)\right]=0
$$

where $H$ is the hardening parameter indicating the hardening degree of soil due to the occurrence of plastic strain $\varepsilon_{r s}^{\mathrm{p}}(r, s=1,2,3)$. In view of the superior abilities of $c_{i j}$ in reflecting 3D properties of soil only through two characteristic stress invariants $c_{\mathrm{n}}$ and $c_{\mathrm{s}}{ }^{[19]}$, the yield function can be written as:

$$
f=f\left[c_{\mathrm{n}}, c_{\mathrm{s}}, H\left(\varepsilon_{r s}^{\mathrm{p}}\right)\right]=0
$$

where $c_{\mathrm{n}}$ and $c_{\mathrm{s}}$ are the mean characteristic principal stress and the characteristic shear stress, respectively.

By applying the non-orthogonal plastic flow rule in Eq. (2) to the yield function in Eq. (4), the plastic flow direction $m_{i j}$ in tensor form can be derived in the $c_{i j}$ space:

$$
m_{i j}=\frac{\partial^{\mu} f}{\partial c_{\mathrm{n}}^{\mu}} \frac{\partial c_{\mathrm{n}}}{\partial c_{i j}}+\frac{\partial^{\mu} f}{\partial c_{\mathrm{s}}^{\mu}} \frac{\partial c_{\mathrm{s}}}{\partial c_{i j}}
$$

The plastic multiplier $\Lambda$ can be determined by the consistency condition, which is the total differential of the yield function $f=0$ in the $c_{i j}$ space: 


$$
\mathrm{d} f=\frac{\partial f}{\partial c_{i j}} \mathrm{~d} c_{i j}+\frac{\partial f}{\partial H} \frac{\partial H}{\partial \varepsilon_{r s}^{\mathrm{p}}} \mathrm{d} \varepsilon_{r s}^{\mathrm{p}}=0
$$

Where $\varepsilon_{r s}^{\mathrm{p}}$ is the plastic strain used for constructing the hardening parameter $H$. By substituting $\mathrm{d} \varepsilon_{r s}^{\mathrm{p}}=\Lambda \cdot m_{r s}$ from Eq. (2) into Eq. (6), $\Lambda$ can thus be expressed as:

$$
\Lambda=-\frac{\frac{\partial f}{\partial c_{i j}} \mathrm{~d} c_{i j}}{\frac{\partial f}{\partial H} \frac{\partial H}{\partial \varepsilon_{r s}^{\mathrm{p}}} m_{r s}}
$$

By substituting the plastic flow direction $m_{i j}$ in Eq. (5) and the plastic multiplier $\Lambda$ in Eq. (7) into Eq. (2), the plastic strain increment in the tensor form can be written as:

$$
\mathrm{d} \varepsilon_{i j}^{\mathrm{p}}=\Lambda \cdot m_{i j}=-\frac{\frac{\partial f}{\partial c_{i j}} \mathrm{~d} c_{i j}}{\frac{\partial f}{\partial H} \frac{\partial H}{\partial \varepsilon_{r s}^{\mathrm{p}}} m_{r s}} \cdot\left(\frac{\partial^{\mu} f}{\partial c_{\mathrm{n}}^{\mu}} \frac{\partial c_{\mathrm{n}}}{\partial c_{i j}}+\frac{\partial^{\mu} f}{\partial c_{\mathrm{s}}^{\mu}} \frac{\partial c_{\mathrm{s}}}{\partial c_{i j}}\right)
$$

For the elastic strain increment in Eq. (1), we can make use of the elastic theory, e.g. Hooke's law:

$$
\mathrm{d} \varepsilon_{i j}^{\mathrm{e}}=\frac{1+v}{E} \mathrm{~d} \sigma_{i j}-\frac{v}{E} \mathrm{~d} \sigma_{k k} \delta_{i j}
$$

where $v$ is the Poisson's ratio. $E$ is the Young's modulus, which can be obtained from the $e$-ln $p$ relationship of the swelling line under the isotropic compression conditions:

$$
E=3(1-2 v) \frac{1+e_{0}}{\kappa} p
$$

where $\kappa$ is the swelling index, and $e_{0}$ is the initial void ratio at $p=p_{0}$.

Finally, by substituting Eqs. (9) and (8) into Eq. (1), the total strain increment is thus determined within the framework of the 3D non-orthogonal elastoplastic model.

\section{Formulation of 3D non-orthogonal model}

Within the framework of the non-orthogonal plastic theory, the yield function plays the key role in determining $\Lambda$ and $m_{i j}$. In this paper, the improved elliptic yield function in the $c_{i j}$ space is adopted.

$$
f=c_{\mathrm{s}}^{2}+N^{2}\left(c_{\mathrm{n}}^{2}-c_{\mathrm{n} x} c_{\mathrm{n}}\right)=0
$$

where $N$ is the ratio of the vertical axis to the horizontal axis of the elliptic yield curve as shown in 
Fig. 2, which can be determined by the method in Section 3.4 based on the phase transition stress ratio $F$. The equivalent characteristic consolidation pressure $c_{\mathrm{n} x}$ is the intersection of $f$ with the mean stress axis and defines the position of the yield surface, which can be expressed by the current stress state as follows:

$$
c_{\mathrm{n} x}=\frac{c_{\mathrm{s}}^{2}+N^{2} c_{\mathrm{n}}^{2}}{N^{2} c_{\mathrm{n}}}
$$

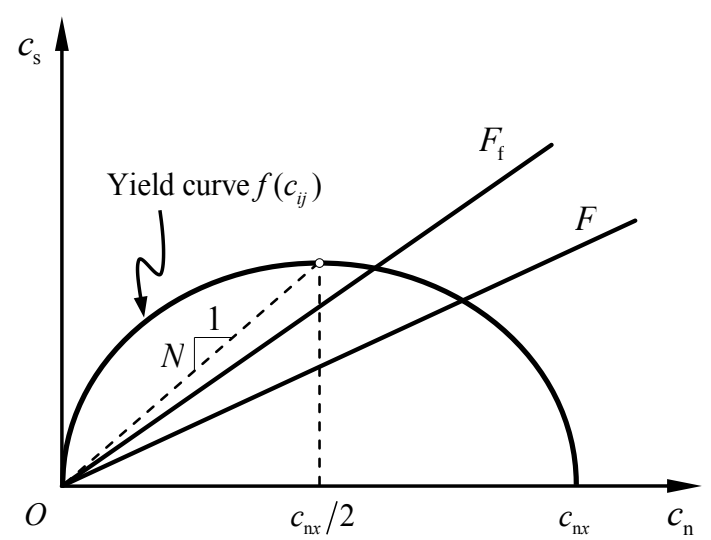

Fig. 2 Yield curve in the characteristic stress space.

Note that our yield function can also reduce to the yield function of the modified Cam-clay model ${ }^{[25]}$ when $\beta=1$ and $N=M$. As shown by Lu et al. ${ }^{[19]}$, the axisymmetric ellipsoidal yield surface in the $c_{i j}$ space corresponds to a smooth and convex triaxial symmetric yield surface in the $\sigma_{i j}$ space. That is, in the $\sigma_{i j}$ space, the asymmetric curve with respect to the $p$-axis in the meridian plane and the curved triangle in the deviatoric plane can both be directly described by the simple expression in the $c_{i j}$ space (i.e., Eq. (11)). Therefore, the $\theta$ effect and stress-induced anisotropy of geomaterials can be reasonably captured by the yield function.

\subsection{D non-orthogonal plastic flow direction}

In this paper, the non-orthogonal plastic flow direction is expressed based on the Caputo fractional derivative operator. The specific expressions and properties of the Caputo fractional derivative operator involved in this paper are provided in Appendix B.

By applying the non-orthogonal plastic flow rule in Eq. (2) to the yield function in Eq. (11), and further incorporating Eq. (12) and the recursive properties of the Gamma function $\Gamma(x+1)=x \cdot \Gamma(x)$, the non-orthogonal gradient $\boldsymbol{m}=\left(m_{\mathrm{n}}, m_{\mathrm{s}}\right)$ of the yield function can be expressed as:

$$
\boldsymbol{m}=\left(m_{\mathrm{n}}, m_{\mathrm{s}}\right)=\left(\frac{\mu N^{2} c_{\mathrm{n}}^{2}+(\mu-2) c_{\mathrm{s}}^{2}}{\Gamma(3-\mu) c_{\mathrm{n}}^{\mu}}, \frac{2 c_{\mathrm{s}}^{2-\mu}}{\Gamma(3-\mu)}\right)
$$


Furthermore, by combining Eq. (13) with the coordinate transformation coefficient $\partial c_{\mathrm{n}} / \partial c_{i j}=\delta_{i j} / 3$ and $\partial c_{\mathrm{s}} / \partial c_{i j}=3 / 2 \cdot\left(c_{i j}-c_{\mathrm{n}} \delta_{i j}\right) / c_{\mathrm{s}}$, the plastic flow direction tensor $m_{i j}$ can thus be obtained:

$$
m_{i j}=\frac{\mu N^{2} c_{\mathrm{n}}^{2}+(\mu-2) c_{\mathrm{s}}^{2}}{\Gamma(3-\mu) c_{\mathrm{n}}^{\mu}} \frac{\delta_{i j}}{3}+\frac{2 c_{\mathrm{s}}^{2-\mu}}{\Gamma(3-\mu)} \frac{3\left(c_{i j}-c_{\mathrm{n}} \delta_{i j}\right)}{2 c_{\mathrm{s}}}
$$

\subsubsection{Plastic flow direction in the $c_{i j}$ space}

The evolution of the plastic flow direction with the expansion of the yield surface will be illustrated, and its capability to model the dilatancy of sand will be explored as follows. To gain perspectives, let us consider the following material parameters for demonstration purpose: $M=0.95$, $M_{\mathrm{f}}=1.65$ and $\beta=0.4$, which are typical for dense sand. Therefore, the phase transition stress ratio $F=0.366$ and the failure stress ratio $F_{\mathrm{f}}=0.664$ are correspondingly obtained based on expressions listed in Tab. A-1 (see Appendix A), and $N=0.62$ and $\mu=0.52$ can be determined by the method in Section 3.4. Typical stress paths under true triaxial conditions under $p=196 \mathrm{kPa}$ at different stress Lode angles $\theta\left(\theta=0^{\circ}, 15^{\circ}, 30^{\circ}, 45^{\circ}\right.$ and $\left.60^{\circ}\right)$ are used for illustrating the variation rule of the plastic flow direction.

The simple expression of the yield function makes the yield surface in a simple ellipsoidal shape in the $c_{i j}$ space, and the ellipsoidal yield surface expands only when the size changes without changing shape, as shown in Fig. 3. The elliptic yield curve in the meridian plane and the circular yield curve in the deviatoric plane are shown in Fig. 4(a) and (b), respectively. With the expansion of the ellipsoidal yield surface, the plastic flow directions for $\mu=0.52$ and $\mu=1.00$ correspondingly change, as shown in Fig. 3 and Fig. 4. The plastic flow direction non-orthogonal to the yield surface when $\mu=0.52$ is represented by the red arrow, and the plastic flow direction orthogonal to the yield surface when $\mu=1.00$ is represented by the black arrow. As the shear stress increases in the meridian plane, the non-orthogonal plastic flow direction shown in Fig. 4(a) changes from horizontal to the right at $\chi=0$ to vertically upward at $\chi=F$ for describing the negative dilatancy, and finally turns to the direction pointing to the left until $\chi$ reaches $F_{\mathrm{f}}$ for capturing the positive dilatancy. As for the plastic flow direction in the deviatoric plane, it is independent of the fractional-order $\mu$, since no variable associated with the stress Lode angle contains in the yield function. That is, the plastic flow directions in the deviatoric plane for $\mu=0.52$ coincide with the plastic flow directions for $\mu=1$. Here, the coincident plastic flow directions are represented by the red arrows, as shown in Fig. 4(b). The plastic flow direction in the deviatoric plane is the radial direction along the current characteristic 
stress Lode angle $\theta_{\beta}$ defined in Tab. A-1 (see Appendix A). The $\theta_{\beta}$-values on the stress paths under the condition that $\theta=0^{\circ}$ and $60^{\circ}$ are constant, while $\theta_{\beta}$-values on the characteristic stress paths at $\theta=15^{\circ}, 30^{\circ}$ and $45^{\circ}$ are changeable and increase with increasing shear stress. Therefore, the plastic flow directions along the radial direction change with $\theta_{\beta}$-values accordingly, as shown in Fig. 4(b).

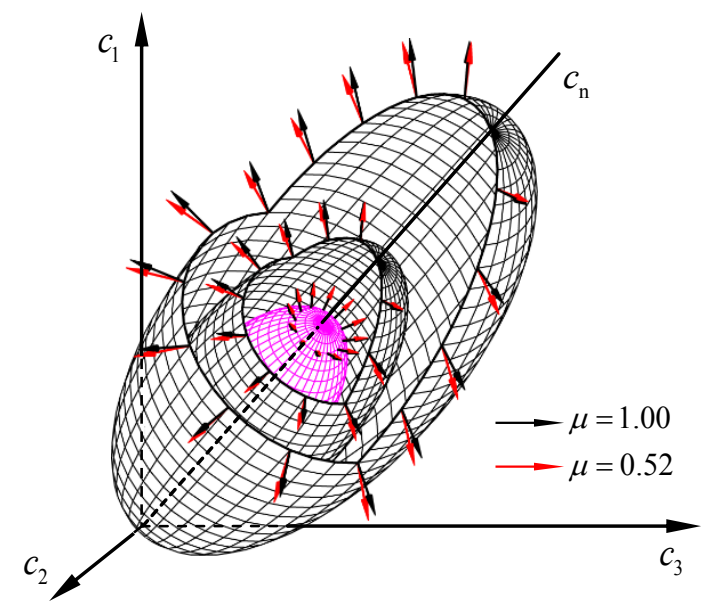

Fig. 3 Evolution of the non-orthogonal plastic flow direction with the expanding yield surface in the $c_{i j}$ space.

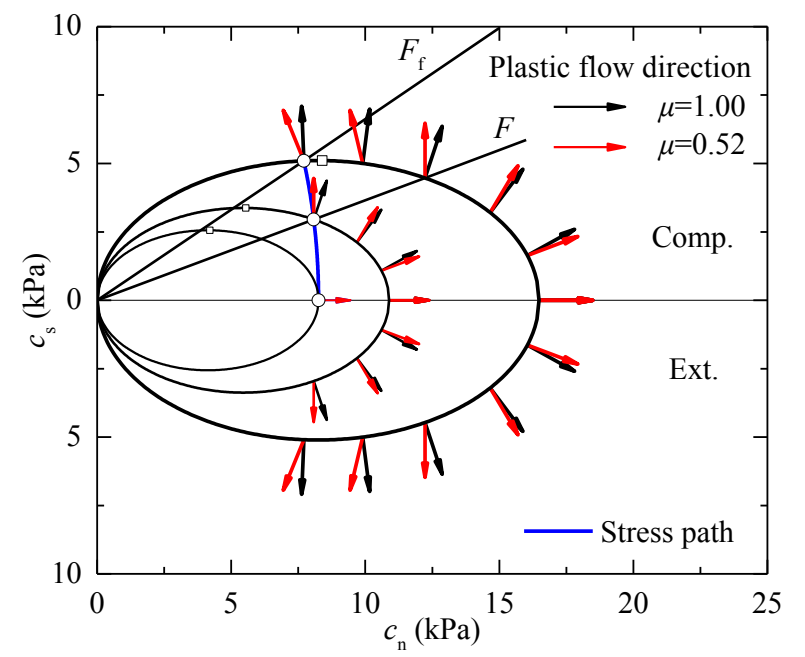

(a)

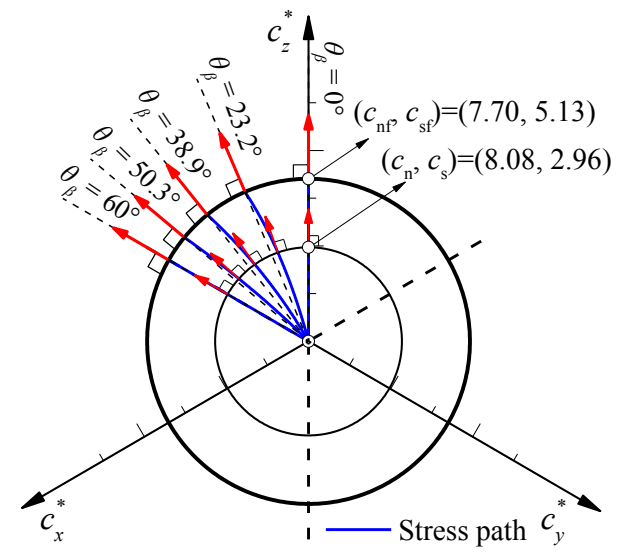

(b)

Fig. 4 Yield curve and non-orthogonal plastic flow direction in (a) the meridian plane of the $c_{i j}$ space and (b) the deviatoric plane of the $c_{i j}$ space.

\subsubsection{Plastic flow direction in the $\sigma_{i j}$ space}

The expansion of the ellipsoidal yield surface in the $c_{i j}$ space corresponds to the evolution of the yield surface in the $\sigma_{i j}$ space, as shown in Fig. 5. The plastic flow direction determined in the $c_{i j}$ 
space is applied to the corresponding stress state point on the yield surface in the $\sigma_{i j}$ space. Corresponding to the expansion of the elliptic yield curve shown in Fig. 4(a), the evolution of the unsymmetrical yield curves in the meridian plane of the $\sigma_{i j}$ space is shown in Fig. 6(a). As the shear stress increases along the stress path under triaxial compression conditions with a constant $p$, the plastic flow direction in Fig. 6(a) changes in the same way as that in Fig. 4(a). It changes from horizontal at stress ratio $\eta=0$ to vertically upward at $\eta=M$ and finally turns to the direction pointing to the left until $\eta$ reaches $M_{\mathrm{f}}$ for capturing the dilatancy behaviour from negative to positive. In the deviatoric plane of the $\sigma_{i j}$ space, the yield curve tends to change from an approximate circle to a curved triangle with the increase of $\eta$, and the plastic flow directions at different $\theta$-values correspondingly change, as shown in Fig. 6(b). The plastic flow directions at $\theta=0^{\circ}$ and $60^{\circ}$ coincide with the radial directions, while the plastic flow directions at $\theta=15^{\circ}, 30^{\circ}$ and $45^{\circ}$ deviate leftward from the radial direction, and the degree of the deviation increases with the increase of $\eta$. This means the stress-induced anisotropy associated with the yield behaviour and plastic flow direction is reflected.

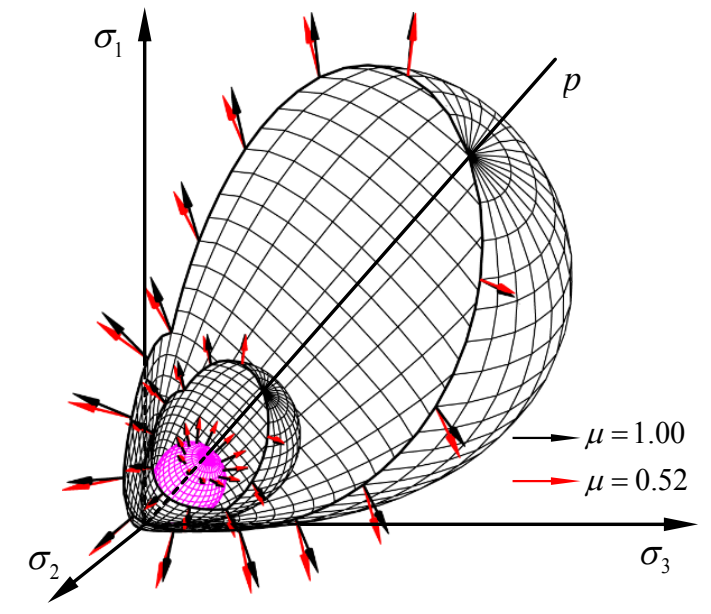

Fig. 5 Evolution of the yield surface and the non-orthogonal plastic flow direction in the $\sigma_{i j}$ space. 


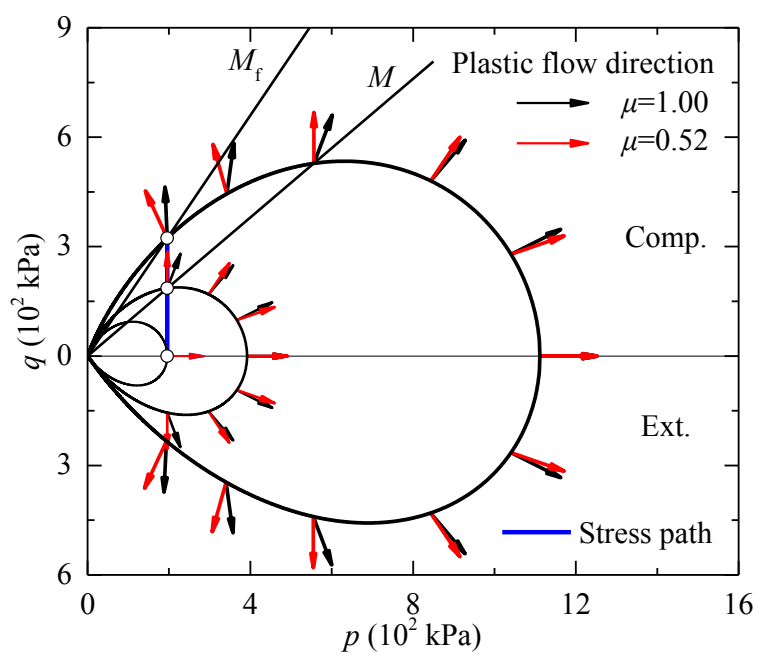

(a)

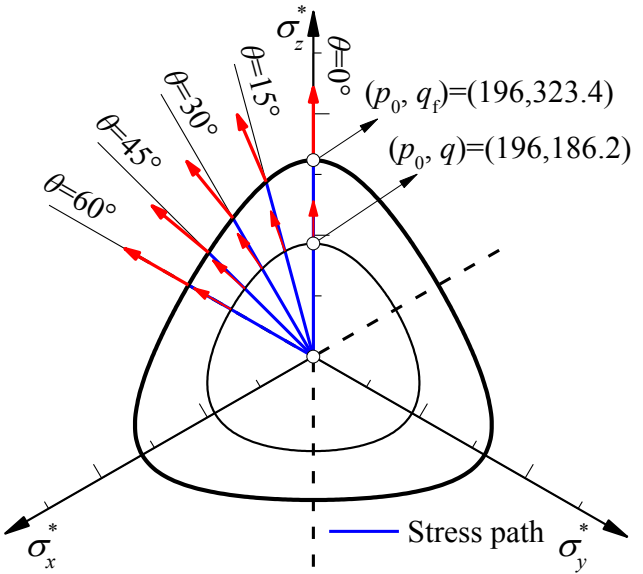

(b)

Fig. 6 Yield curve and non-orthogonal plastic flow direction in (a) the meridian plane of the $\sigma_{i j}$ space and (b) the deviatoric plane of the $\sigma_{i j}$ space.

The above analysis illustrates that the non-orthogonal plastic flow rule ${ }^{[19]}$ and the characteristic stress ${ }^{[40]}$ are complementary in capturing soil behaviours under 3D stress conditions. The nonorthogonal plastic flow rule makes the plastic flow direction suitable for capturing the dilatancy of sand from negative to positive, while the characteristic stress extends the ability to capture dilatancy to $3 \mathrm{D}$ stress conditions. The combination of these two concepts gives rise to a new approach to capture the plastic flow direction for the sand under 3D stress conditions.

\subsection{Hardening parameter for sand with dilatancy}

Hardening parameter is an internal variable reflecting the hardening behaviours during the loading process. It is closely related to the determination of the plastic multiplier $\Lambda$ in Eq. (7). In order to incorporate the dilatancy of sand from negative to positive into a non-orthogonal model, the hardening parameter should be formulated to be coordinated with the plastic flow direction. During the construction process, the hardening parameter should also be independent of the stress path ${ }^{[8,29]}$. Obviously, the plastic volumetric strain as a hardening parameter is effective for normally consolidated clay. However, it is not suitable for describing initial negative and subsequent positive dilatancy of sand. By referring to the method proposed by Yao et al. ${ }^{[8]}$, a stress-path-dependency factor $\Omega$ is introduced and combined with the volumetric strain to construct the hardening parameter $H$, which aims to make $H$ stress-path-independent and capable of capturing the dilatancy of sand. 


$$
H=\int \Omega \mathrm{d} \varepsilon_{\mathrm{v}}^{\mathrm{p}}
$$

For normally consolidated clay, $\varepsilon_{\mathrm{v}}^{\mathrm{p}}$ is used as the hardening parameter, so $\Omega=1$ is obtained.

The relationship $\varepsilon_{\mathrm{v}}^{\mathrm{p}}=l_{\mathrm{p}} \ln c_{\mathrm{n} x} / c_{\mathrm{n} 0}$ can be derived based on the linear relationship between $e$ and $\ln \left(c_{\mathrm{n}}\right)$ under isotropic compression conditions ${ }^{[19]}$, where $l_{\mathrm{p}}=(\lambda-\kappa) /\left[\beta \cdot\left(1+e_{0}\right)\right]$, and $\lambda$ is the compression index. Therefore, the equivalent characteristic consolidation pressure can be expressed as $c_{\mathrm{n} x}=c_{\mathrm{n} 0} \exp \left(\varepsilon_{\mathrm{v}}^{\mathrm{p}} / l_{\mathrm{p}}\right)$. For sand, $H$ in Eq. (15) is adopted to replace $\varepsilon_{\mathrm{v}}^{\mathrm{p}}, c_{\mathrm{n} x}$ can thus be expressed as:

$$
c_{\mathrm{n} x}=c_{\mathrm{n} 0} \exp \left(\frac{H}{l_{\mathrm{p}}}\right)=c_{\mathrm{n} 0} \exp \left\lfloor\frac{1}{l_{\mathrm{p}}} \int \Omega \mathrm{d} \varepsilon_{\mathrm{v}}^{\mathrm{p}}\right\rfloor
$$

The partial derivative of the yield function $f$ with respect to $\varepsilon_{\mathrm{v}}^{\mathrm{p}}$ is required for determining $\Lambda$ in Eq.

(7) and can be obtained based on Eqs. (11) and (16):

$$
\frac{\partial f}{\partial \varepsilon_{\mathrm{v}}^{\mathrm{p}}}=\frac{\partial f}{\partial c_{\mathrm{n} x}} \frac{\partial c_{\mathrm{n} x}}{\partial \varepsilon_{\mathrm{v}}^{\mathrm{p}}}=-\frac{\Omega}{l_{\mathrm{p}}} N^{2} c_{\mathrm{n}} c_{\mathrm{n} x}
$$

In addition, the following differential equation is also needed and can be derived from Eq. (11):

$$
\frac{\partial f}{\partial c_{i j}} \mathrm{~d} c_{i j}=N^{2}\left(2 c_{\mathrm{n}}-c_{\mathrm{n} x}\right) \mathrm{d} c_{\mathrm{n}}+2 c_{\mathrm{s}} \mathrm{d} c_{\mathrm{s}}
$$

By substituting Eqs. (17) and (18) together with Eq. (12) into Eq. (7), the specific expression of $\Lambda$ is obtained:

$$
\Lambda=\frac{l_{\mathrm{p}}}{\Omega} \frac{\left(N^{2} c_{\mathrm{n}}^{2}-c_{\mathrm{s}}^{2}\right) \mathrm{d} c_{\mathrm{n}}+2 c_{\mathrm{s}} c_{\mathrm{n}} \mathrm{d} c_{\mathrm{s}}}{c_{\mathrm{n}}\left(c_{\mathrm{s}}^{2}+N^{2} c_{\mathrm{n}}^{2}\right) m_{\mathrm{n}}}
$$

By substituting $\Lambda$ in Eq. (19) and $\left(m_{\mathrm{n}}, m_{\mathrm{s}}\right)$ in Eq. (13) into Eq. (8), together with the stress ratio $\chi=c_{\mathrm{n}} / c_{\mathrm{s}}$, the plastic volumetric strain and the plastic shear strain can be expressed as:

$$
\left\{\begin{array}{l}
\mathrm{d} \varepsilon_{\mathrm{v}}^{\mathrm{p}}=\Lambda \cdot m_{\mathrm{n}}=\frac{l_{\mathrm{p}}}{\Omega} \frac{\left(N^{2}-\chi^{2}\right) \mathrm{d} c_{\mathrm{n}}+2 \chi \mathrm{d} c_{\mathrm{s}}}{c_{\mathrm{n}}\left(\chi^{2}+N^{2}\right)} \\
\mathrm{d} \varepsilon_{\mathrm{s}}^{\mathrm{p}}=\Lambda \cdot m_{\mathrm{s}}=\frac{l_{\mathrm{p}}}{\Omega} \frac{\left(N^{2}-\chi^{2}\right) \mathrm{d} c_{\mathrm{n}}+2 \chi \mathrm{d} c_{\mathrm{s}}}{c_{\mathrm{n}}\left(\chi^{2}+N^{2}\right)} \frac{2 \chi^{2-\mu}}{\mu N^{2}-(2-\mu) \chi^{2}}
\end{array}\right.
$$

The two stress paths shown in Fig. 7, include the constant mean characteristic principal stress path $A B$ and the isotropic compression stress path $A C$, are used to derive the stress-path-dependent 


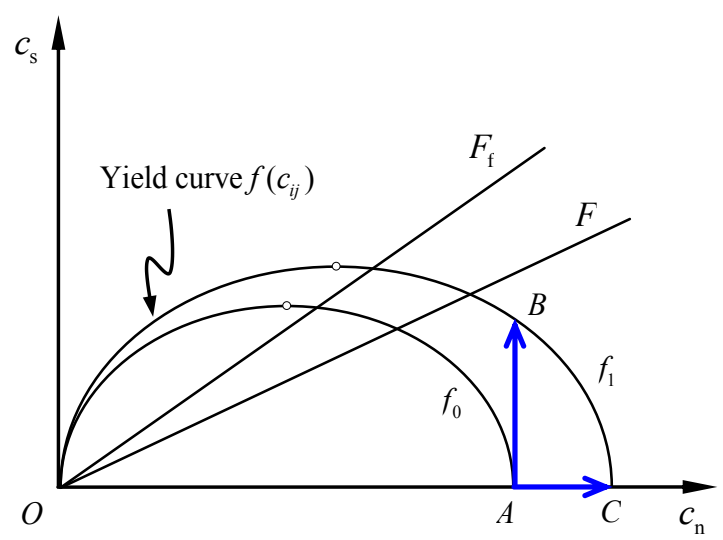

Fig. 7 Stress paths for deriving the hardening parameter $H$.

\subsubsection{Constant mean characteristic principal stress path $A B\left(\mathrm{~d} c_{\mathrm{n}}=0\right)$}

Along the stress path $A B, \mathrm{~d} c_{\mathrm{n}}=0$ and $c_{\mathrm{n}}$ is a constant. Therefore, $\mathrm{d} \varepsilon_{\mathrm{s}}^{\mathrm{p}}$ in Eq. (20) can be simplified as:

$$
\mathrm{d} \varepsilon_{\mathrm{s}}^{\mathrm{p}}=\frac{1}{\Omega} \frac{4 l_{\mathrm{p}} \chi^{3-\mu} \mathrm{d} \chi}{\left(\chi^{2}+N^{2}\right)\left[\mu N^{2}-(2-\mu) \chi^{2}\right]}
$$

For the normally consolidated clay, $\Omega=1 . \mathrm{d} \varepsilon_{\mathrm{s}}^{\mathrm{p}}$ is expressed as:

$$
\mathrm{d} \varepsilon_{\mathrm{s}}^{\mathrm{p}}=\frac{4 l_{\mathrm{p}} \chi^{3-\mu} \mathrm{d} \chi}{\left(N^{2}+\chi^{2}\right)\left[\mu N^{2}-(2-\mu) \chi^{2}\right]}
$$

Similar to Eq. (22), the expression of $\mathrm{d} \varepsilon_{\mathrm{s}}^{\mathrm{p}}$ for sand can be assumed as:

$$
\mathrm{d} \varepsilon_{\mathrm{s}}^{\mathrm{p}}=\rho \frac{4 l_{\mathrm{p}} \chi^{3-\mu} \mathrm{d} \chi}{\left(N_{\mathrm{f}}^{2}+\chi^{2}\right)\left[\mu N_{\mathrm{f}}^{2}-(2-\mu) \chi^{2}\right]}
$$

Here, $\rho$ is an undetermined coefficient that reflects the ratio of the magnitude of $\mathrm{d} \varepsilon_{\mathrm{s}}^{\mathrm{p}}$ between clay and sand along the stress path $A B . N$ in Eq. (22) is changed to $N_{\mathrm{f}}$ that related to the failure stress ratio $F_{\mathrm{f}}$ of sand. In fact, $F_{\mathrm{f}}$ is not constant in describing the shearing process with some complex behaviours, but for the sake of simplicity, it is assumed to be a constant. When sand reaches its failure state at $\chi=F_{\mathrm{f}}$, the expression of $\mathrm{d} \varepsilon_{\mathrm{s}}^{\mathrm{p}}$ in Eq. (23) approaches infinity, which is similar to Eq.

(22) for clay. Thus, $N_{\mathrm{f}}=F_{\mathrm{f}} \sqrt{2 / \mu-1}$ can be obtained.

Furthermore, by combining Eq. (21) with Eq. (23), the stress-path-dependent factor $\Omega$ is 
derived and can be expressed as:

$$
\Omega=\frac{1}{\rho} \frac{(2-\mu)\left(F_{\mathrm{f}}^{2}-\chi^{2}\right)\left[(2-\mu) F_{\mathrm{f}}^{2}+\mu \chi^{2}\right]}{\mu\left(N^{2}+\chi^{2}\right)\left[\mu N^{2}-(2-\mu) \chi^{2}\right]}
$$

Substituting Eq. (24) into Eq. (15) yields:

$$
H=\int \frac{1}{\rho} \frac{(2-\mu)\left(F_{\mathrm{f}}^{2}-\chi^{2}\right)\left[(2-\mu) F_{\mathrm{f}}^{2}+\mu \chi^{2}\right]}{\mu\left(N^{2}+\chi^{2}\right)\left[\mu N^{2}-(2-\mu) \chi^{2}\right]} \mathrm{d} \varepsilon_{\mathrm{v}}^{\mathrm{p}}
$$

\subsubsection{Isotropic compression stress path $A C\left(\mathrm{~d} c_{\mathrm{s}}=0\right)$}

Under isotropic compression conditions ( $\left(\mathrm{d} c_{\mathrm{s}}=0\right), \chi$ is equal to 0 . Eq. (25) can thus be simplified as follows:

$$
H=\int \frac{1}{\rho} \frac{(2-\mu)^{2} F_{\mathrm{f}}^{4}}{\mu^{2} N^{4}} \mathrm{~d} \varepsilon_{\mathrm{v}}^{\mathrm{p}}
$$

Along stress path $A C$, only the plastic volumetric strain $\varepsilon_{\mathrm{v}}^{\mathrm{p}}$ occurs for sand. That is, $H=\int \mathrm{d} \varepsilon_{\mathrm{v}}^{\mathrm{p}}$ can be used to depict the hardening rule of sand under isotropic compression conditions. The expression of $\rho$ can thus be derived by combining $H=\int \mathrm{d} \varepsilon_{\mathrm{v}}^{\mathrm{p}} \quad$ with Eq. (26).

$$
\frac{1}{\rho}=\frac{\mu^{2} N^{4}}{(2-\mu)^{2} F_{\mathrm{f}}^{4}}
$$

By substituting Eq. (27) into Eq. (24), the stress-path-dependent factor $\Omega$ can be expressed as:

$$
\Omega=\frac{\mu N^{4}}{(2-\mu) F_{\mathrm{f}}^{4}} \frac{\left(F_{\mathrm{f}}^{2}-\chi^{2}\right)\left[(2-\mu) F_{\mathrm{f}}^{2}+\mu \chi^{2}\right]}{\left(N^{2}+\chi^{2}\right)\left[\mu N^{2}-(2-\mu) \chi^{2}\right]}
$$

Finally, the new hardening parameter is obtained by substituting Eq. (28) into Eq. (15) and can be expressed as follows:

$$
H=\int \frac{\mu N^{4}}{(2-\mu) F_{\mathrm{f}}^{4}} \frac{\left(F_{\mathrm{f}}^{2}-\chi^{2}\right)\left[(2-\mu) F_{\mathrm{f}}^{2}+\mu \chi^{2}\right]}{\left(N^{2}+\chi^{2}\right)\left[\mu N^{2}-(2-\mu) \chi^{2}\right]} \mathrm{d} \varepsilon_{\mathrm{v}}^{\mathrm{p}}
$$

With the proposed hardening parameter $H$, the negative and positive dilatancy behaviours of sand can be described. Typical results of sand behaviours under triaxial compression conditions under $p=$ constant are illustrated by the schematic diagram shown in Fig. 8(a), which is arranged in terms of the stress ratio $\eta=q / p$ and the volumetric strain $\varepsilon_{\mathrm{v}}$ vs. the shear strain $\varepsilon_{\mathrm{s}}$. Since $p=$ constant, $\varepsilon_{i j}^{\mathrm{e}}=0$ and $\varepsilon_{i j}=\varepsilon_{i j}^{\mathrm{p}}$ are obtained. The negative and positive dilatancy can be explained and indicated by the following equation derived from Eq. (29). Moreover, corresponding to Fig. 8(a), 
the following conclusions listed in Tab. 1 can be drawn from Eq. (30) based on the non-negative $\mathrm{d} H$.

$$
\mathrm{d} \varepsilon_{\mathrm{v}}^{\mathrm{p}}=\frac{(2-\mu) F_{\mathrm{f}}^{4}}{\mu N^{4}} \frac{\left(N^{2}+\chi^{2}\right)\left[\mu N^{2}-(2-\mu) \chi^{2}\right]}{\left(F_{\mathrm{f}}^{2}-\chi^{2}\right)\left[(2-\mu) F_{\mathrm{f}}^{2}+\mu \chi^{2}\right]} \mathrm{d} H
$$

Tab. 1 Variation rule of $\mathrm{d} \varepsilon_{\mathrm{v}}^{\mathrm{p}}$ with the increase of stress ratio $\eta$

\begin{tabular}{ccccc}
\hline Stress state & Characteristic stress state & $\mathrm{d} H$ & $\mathrm{~d} \varepsilon_{\mathrm{v}}^{\mathrm{p}}$ & Current condition \\
\hline$\eta=0$ & $\chi=0$ & $\mathrm{~d} H=\mathrm{d} \varepsilon_{\mathrm{v}}^{\mathrm{p}}$ & $\mathrm{d} \varepsilon_{\mathrm{v}}^{\mathrm{p}_{\mathrm{v}}}>0$ & Isotropic compression \\
$0<\eta<M$ & $0<\chi<F$ & $\mathrm{~d} H>0$ & $\mathrm{~d} \varepsilon_{\mathrm{v}}^{\mathrm{p}}>0$ & Negative dilatancy \\
$\eta=M$ & $\chi=F$ & $\mathrm{~d} H>0$ & $\mathrm{~d} \varepsilon_{\mathrm{v}}^{\mathrm{p}}=0$ & Phase transition state \\
$M<\eta \leq M_{\mathrm{f}}$ & $F<\chi \leq F_{\mathrm{f}}$ & $\mathrm{d} H>0$ & $\mathrm{~d} \varepsilon_{\mathrm{v}}^{\mathrm{p}<0}$ & Positive dilatancy \\
\hline
\end{tabular}

By adopting $H$ with the properties indicated above, the shear responses transiting from contraction to dilation are captured. When $M_{\mathrm{f}}=M, F_{\mathrm{f}}=F$ can be obtained, $H$ will degenerate to $\varepsilon_{\mathrm{v}}^{\mathrm{p}}$, only negative dilatancy will be described, as shown in Fig. 8(b). For the condition that $\beta=1, c_{i j}$ becomes $\sigma_{i j}, F=M$ and $F_{\mathrm{f}}=M_{\mathrm{f}}$ are obtained. When $N=M, \mu=1$ can be derived, so $H$ can degenerate to the hardening parameter proposed by Yao et al. ${ }^{[8]}$.

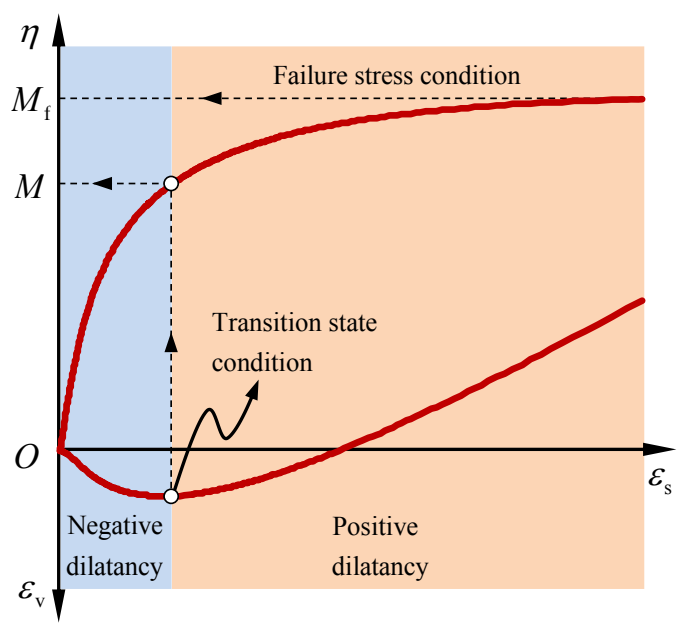

(a)

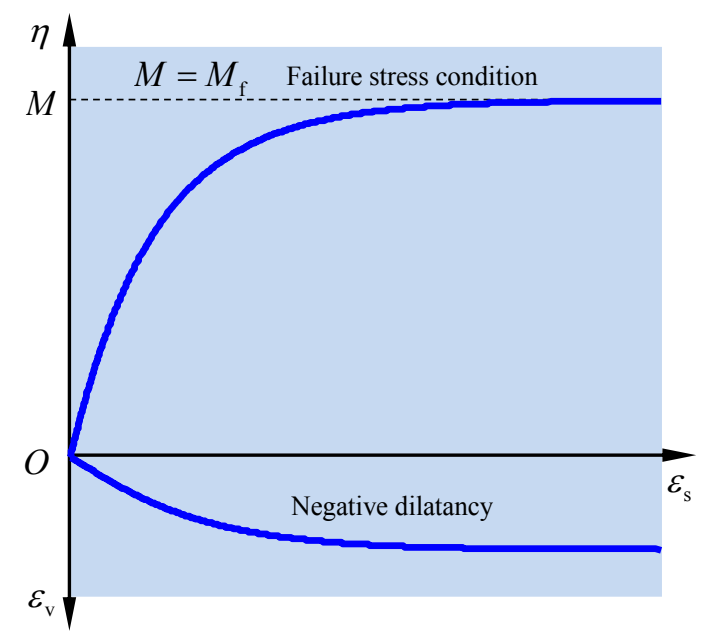

(b)

Fig. 8 Stress-strain relationship of soil with: (a) negative and positive dilatancy; and (b) negative dilatancy. 


\subsubsection{Stress-path-independency of the hardening parameter}

The stress-path-independence of the hardening parameter $H$ can be interpreted the change of $H$ along different paths, as shown in Fig. 9 and Fig. 10. The yield curve passes through the stress state point $A_{0}\left(c_{\mathrm{n} x}, 0\right)$ which is the only intersection point of the yield surface $f_{0}$ and the $c_{\mathrm{n}}$-axis. According to Eq. (16), the unique intersection point corresponds to a unique value of $H_{0}$. That is, the yield surface $f_{0}$ is actually an equivalent surface of $H_{0}$. As the loading continues along different paths to points $B_{1}, C_{1}$ and $D_{1}$ that are all on the yield surface $f_{1}$ as shown in Fig. $9($ a), the yield surface gradually expands, and the intersection moves along the $c_{\mathrm{n}}$-axis to the point $A_{1}\left(c_{\mathrm{nx} x}, 0\right)$. Accordingly, the value of the hardening parameter changes to $H_{1}$, which is equivalent for any stress state on $f_{1}$. Therefore, the difference $\Delta H=H_{1}-H_{0}$ can be calculated and is independent on the stress path. This is exactly the basic properties that hardening parameters need to satisfy. The corresponding yield surface and stress paths in the $\sigma_{i j}$ space are shown in Fig. 9(b). Fig. 10 shows that, as the sand is loaded along different stress paths from $f_{0}$ to $f_{1}$, the value of the $H$ changes from $H_{0}$ to $H_{1}$. The results of equal variation in $H$ shown in Fig. 10 indicates that $H$ is stress-path-independence.

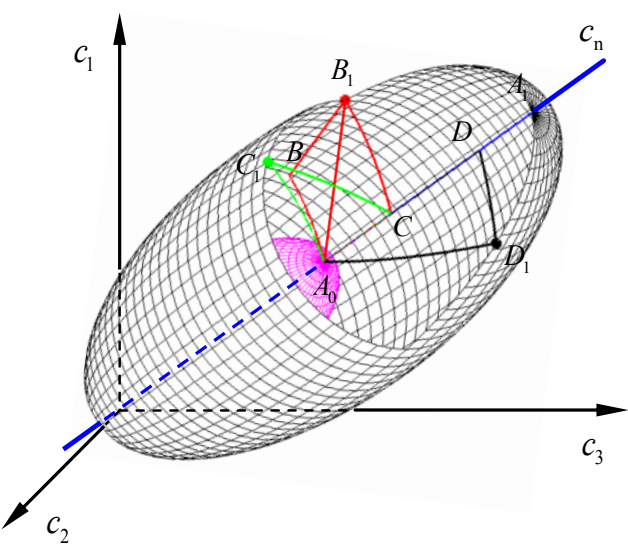

(a)

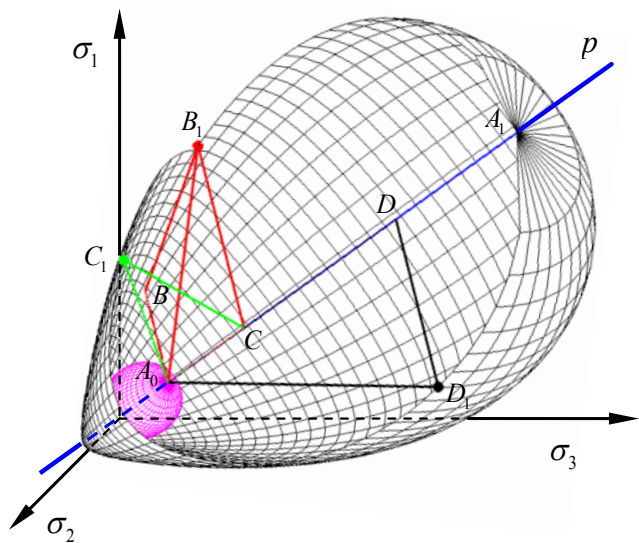

(b)

Fig. 9 Stress paths for verification of the stress-path-independence of $H$ : (a) in the characteristic stress space; (b) in the ordinary stress space. 


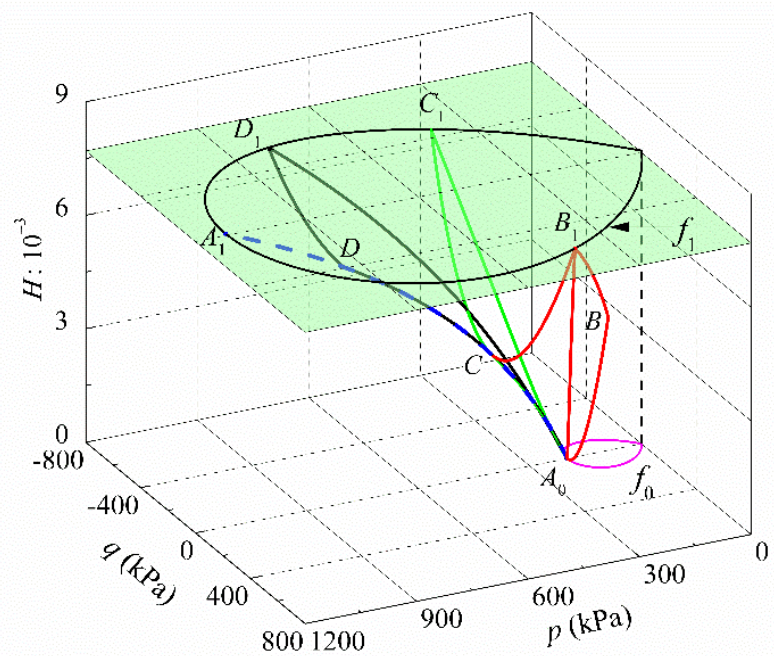

Fig. 10 Stress-path-independence of $H$.

\subsection{Stress-strain relationship}

With the newly derived stress-path-dependent factor $\Omega$, the explicit expression of the plastic multiplier $\Lambda$ can be obtained based on Eq. (19):

$$
\Lambda=l_{\mathrm{p}} \frac{(2-\mu) F_{\mathrm{f}}^{4}}{\mu N^{4}} \frac{\left(N^{2}+\chi^{2}\right)\left[\mu N^{2}-(2-\mu) \chi^{2}\right]}{\left(F_{\mathrm{f}}^{2}-\chi^{2}\right)\left[(2-\mu) F_{\mathrm{f}}^{2}+\mu \chi^{2}\right]} \frac{\left(N^{2} c_{\mathrm{n}}^{2}-c_{\mathrm{s}}^{2}\right) \mathrm{d} c_{\mathrm{n}}+2 c_{\mathrm{s}} c_{\mathrm{n}} \mathrm{d} c_{\mathrm{s}}}{c_{\mathrm{n}}\left(c_{\mathrm{s}}^{2}+N^{2} c_{\mathrm{n}}^{2}\right) m_{\mathrm{n}}}
$$

By substituting Eqs. (14) and (31) into Eq. (2), the plastic strain increment is thus derived:

$$
\mathrm{d} \varepsilon_{i j}^{\mathrm{p}}=l_{\mathrm{p}} \frac{(2-\mu) F_{\mathrm{f}}^{4}\left[\mu N^{2}-(2-\mu) \chi^{2}\right]\left[\left(N^{2}-\chi^{2}\right) \mathrm{d} c_{\mathrm{n}}+2 \chi \mathrm{d} c_{\mathrm{s}}\right]}{\mu N^{4} c_{\mathrm{n}}\left(F_{\mathrm{f}}^{2}-\chi^{2}\right)\left[(2-\mu) F_{\mathrm{f}}^{2}+\mu \chi^{2}\right]} \cdot\left[\frac{\delta_{i j}}{3}+\frac{3 \chi^{1-\mu}\left(c_{i j} / c_{\mathrm{n}}-\delta_{i j}\right)}{\mu N^{2}-(2-\mu) \chi^{2}}\right]
$$

The expression of plastic strain increment is totally expressed by the characteristic stress, and thus naturally, the $\beta$ criterion is used as the shear failure condition of sand. When $M_{\mathrm{f}}=M, F_{\mathrm{f}}=F$ can be obtained, and Eq. (32) can thus be simplified to determine the plastic strain increment for the loose sand with only negative dilatancy.

The total strain increment produced by the current stress increment can thus be obtained by Eq. (1), where the elastic strain increment for sand is expressed by Eq. (9) and the plastic strain increment is expressed by Eq. (32). The parameters involved in the non-orthogonal elastoplastic model can be easily determined, which will be discussed in the following section.

\subsection{Parameter calibration}

There are seven independent material parameters in the proposed model, i.e., $\lambda, \kappa, \nu, \varphi, \varphi_{\mathrm{f}}, \beta$ and $\xi$. All material parameters have clear physical meaning and can be easily determined by conventional triaxial tests. The parameters $\lambda, \kappa$ and $v$ are the same with the parameters of the 
modified Cam-clay model. The parameters $\varphi$ and $\varphi_{\mathrm{f}}$ are the internal friction angles of the sand under triaxial compression conditions at the phase transition state and the failure state, respectively. $\beta$ is the characteristic stress index, which can be determined based on the expression of the characteristic failure stress ratio $F_{\mathrm{f}}$ listed in Tab. A-1 (see Appendix A). Actually, $F_{\mathrm{f}}$ can be determined by combining the internal friction angle $\varphi_{\mathrm{fb}}$ at any intermediate principal stress coefficient $b$ ( $b=\left(\sigma_{2}-\right.$ $\left.\left.\sigma_{3}\right) /\left(\sigma_{1}-\sigma_{3}\right)\right)$ with $\beta$ based on the expression of the $\beta$ criterion in Eq. (39). Note the value of $F_{\mathrm{f}}$ is independent of $b$, i.e., $\left.\quad F_{\mathrm{f}}\right|_{b_{1}}=\left.F_{\mathrm{f}}\right|_{b_{2}}$, where the subscripts $b_{1}$ and $b_{2}$ are two different $b$-values. Based on this, the parameter $\beta$ can be determined by $\varphi_{b_{1}}$ and $\varphi_{b_{2}}$, which reflects the relative proportional relationship of shear strength at different $b$. In particular, $\varphi_{\mathrm{f}}$ at $b_{1}=0$ and $\varphi_{\mathrm{fe}}$ at $b_{2}=1$ are used to determine $\beta$-value based on the method proposed by Lu et al. ${ }^{[19,40]}$. Parameter $\xi$ is called the spacing ratio $^{[21,30]}$. It can also be used to describe the change of the void ratio $\Delta \Pi$ of sand between the initial state and the phase transition state under triaxial compression conditions under $p=$ const. The change of the void ratio has been derived and expressed as $\Delta \Pi=(\lambda-\kappa) \cdot \ln \left(p_{x} / p_{x 0}\right)^{[21]}$, where $p_{x 0}$ and $p_{x}$ are the equivalent mean principal stresses for the initial state and the phase transition state, respectively. Here, $p_{x} / p_{x 0}=\xi$ is assumed, therefore, $\xi$ can be determined by $\xi=\exp [\Delta \Pi /(\lambda-\kappa)]$, and $\xi=2$ is a special case derived from the modified Cam-clay model.

In addition, $N$ and $\mu$ are two model parameters, which can both be easily determined based on the above material parameters. Their determination is given below.

Since the equivalent mean principal stresses $p_{x 0}$ and $p_{x}$ are both defined for the isotropic compression conditions, the equivalent mean characteristic principal stresses can be expressed as $c_{\mathrm{n} x 0}=p_{\mathrm{r}} \cdot\left(p_{x 0} / p_{\mathrm{r}}\right)^{\beta}$ and $c_{\mathrm{nx} x}=p_{\mathrm{r}} \cdot\left(p_{x} / p_{\mathrm{r}}\right)^{\beta}$. Therefore, based on $\xi=p_{x} / p_{x 0}$ mentioned above, we can get $c_{\mathrm{nx}}=\xi^{\beta} \cdot c_{\mathrm{n} x 0}$. On the other hand, substituting the phase transition stress state $\left(c_{\mathrm{nt}}, c_{\mathrm{st}}\right)=\left(c_{\mathrm{nt}}, F \cdot c_{\mathrm{nt}}\right)$ into Eq. (12) yields:

$$
c_{\mathrm{nx}}=c_{\mathrm{nt}}\left(\frac{F^{2}}{N^{2}}+1\right)
$$

By combining $c_{\mathrm{nx}}=\xi^{\beta} \cdot c_{\mathrm{nx} 0}$ with Eq. (33), $N$ can be derived as:

$$
N=F \sqrt{\frac{c_{\mathrm{nt}}}{\xi^{\beta} c_{\mathrm{nx} 0}-c_{\mathrm{nt}}}}
$$

where $c_{\mathrm{nt}}=\left(c_{1 \mathrm{t}}+2 c_{3 \mathrm{t}}\right) / 3$, in which $c_{1 \mathrm{t}}=p_{\mathrm{r}} \cdot\left(\sigma_{1 \mathrm{t}} / p_{\mathrm{r}}\right)^{\beta}$ and $c_{3 \mathrm{t}}=p_{\mathrm{r}} \cdot\left(\sigma_{3 \mathrm{t}} / p_{\mathrm{r}}\right)^{\beta}$ can be obtained from Tab. A-1. $\sigma_{1 \mathrm{t}}$ and $\sigma_{3 \mathrm{t}}$ are the major and minor principal stresses at the phase transition state, which can be 
calculated from $\sigma_{1 \mathrm{tt}}=p_{x 0}(1+2 M / 3)$ and $\sigma_{3 t}=p_{x 0}(1-M / 3)$, respectively. Therefore, parameter $N$ can be determined by the following equation:

$$
N=F \sqrt{\frac{(1+2 M / 3)^{\beta}+2(1-M / 3)^{\beta}}{3 \xi^{\beta}-(1+2 M / 3)^{\beta}-2(1-M / 3)^{\beta}}}
$$

The shape of the yield surface is known when $N$ is determined. Therefore, the expression of plastic flow direction is obtained, and the stress-dilatancy ratio $d$ can be correspondingly derived:

$$
d=\frac{\mathrm{d} \varepsilon_{\mathrm{v}}^{\mathrm{p}}}{\mathrm{d} \varepsilon_{\mathrm{s}}^{\mathrm{p}}}=\frac{\mu N^{2}-(2-\mu) \chi^{2}}{2 \chi^{2-\mu}}
$$

When the phase transition state reaches, $\chi$ reaches $F$, and $d$ in Eq. (36) is equal to 0 , then the fractional-order $\mu$ can be determined by the following equation:

$$
\mu=\frac{2 F^{2}}{N^{2}+F^{2}}
$$

\section{Model verification}

The performance of the proposed model can be evaluated and verified by comparing model prediction with test results of sand from literature. We consider the tests on saturated Toyoura sand under conventional triaxial compression $\left(\sigma_{3}=p_{0}, p=p_{0}\right.$ and $\left.\sigma_{1}=p_{0}\right)$ and extension $\left(\sigma_{3}=p_{0}, p=p_{0}\right.$ and $\left.\sigma_{1}=p_{0}\right)$ conditions and true triaxial conditions $\left(\theta=15^{\circ}, 30^{\circ} \text { and } 45^{\circ}\right)^{[29]}$. The mean diameter of sand is $0.2 \mathrm{~mm}$, the uniformity coefficient is 1.3 and the specimens were prepared in medium dense with an initial void ratio 0.68 . The material parameters used for model prediction are listed in Tab. 2. The corresponding model parameters $N=0.439$ and $\mu=0.390$ can thus be determined based on the material parameters by the method mentioned in Section 3.4.

Tab. 2 Material parameters used for model prediction.

\begin{tabular}{ccccccc}
\hline$\lambda /\left(1+e_{0}\right)$ & $\kappa /\left(1+e_{0}\right)$ & $v$ & $\varphi$ & $\varphi_{\mathrm{f}}$ & $\beta$ & $\xi$ \\
\hline 0.00403 & 0.00251 & 0.3 & $24.209^{\circ}$ & $40.475^{\circ}$ & 0.24 & 2.3 \\
\hline
\end{tabular}

\subsubsection{Toyoura sand under conventional triaxial conditions}

Test data of saturated Toyoura sand under conventional triaxial compression $\left(\sigma_{3}=p_{0}, p=p_{0}\right.$ and $\left.\sigma_{1}=p_{0}\right)$ and extension $\left(\sigma_{3}=p_{0}, p=p_{0}\right.$ and $\left.\sigma_{1}=p_{0}\right)$ conditions are digitized from ${ }^{[8]}$ and indicated by open circles, as shown in Fig. 11. As shown in Fig. 11(a) and (b), the negative dilatancy of sand is obvious, since $p$ increases under triaxial compression and extension conditions when $\sigma_{3}=p_{0}$. Less negative dilatancy can be found in Fig. 11(c) and (d), since a constant $p$ is applied. Moreover, due to the 
decrease of $p$ under triaxial compression and extension conditions when $\sigma_{1}=p_{0}$, the least negative dilatancy is found in Fig. 11(e) and (f). The test results of Toyoura sand along six different stress paths are predicted, as shown in Fig. 11(a)-(f). Due to the contributions of the non-orthogonal plastic flow direction and the newly constructed $H$, different degrees of dilatancy from negative to positive along six different stress paths are well predicted. Comparisons between the test results and the prediction show that the relationship of $\varepsilon_{1}$ vs. $\sigma_{1} / \sigma_{3}$ and $\varepsilon_{1}$ vs. $\sigma_{1} / \sigma_{3}$ is also well captured by the proposed model. On the other hand, benefit from the application of characteristic stress, the $\beta$ criterion is naturally used in the model, and thus the tendency that the shear strength of the sand under extension conditions is greater than that under compression conditions can be well reflected.

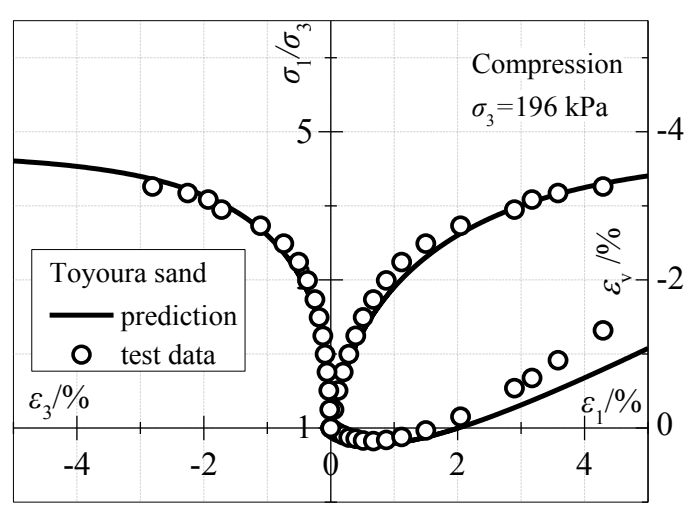

(a) Compression when $\sigma_{3}=p_{0}$

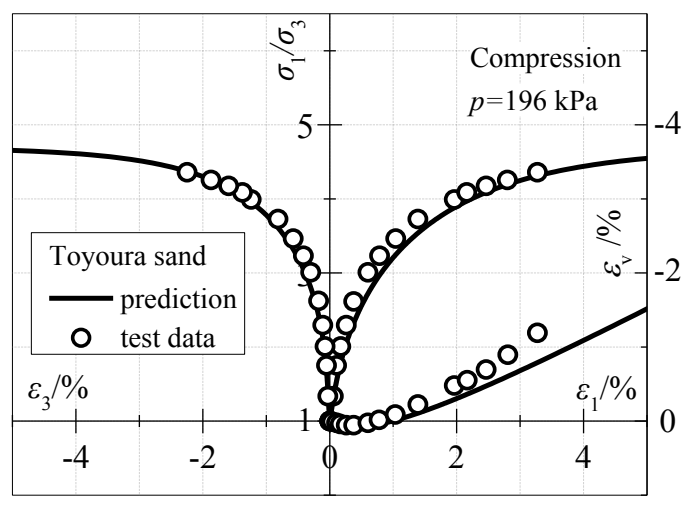

(c) Compression when $p=p_{0}$

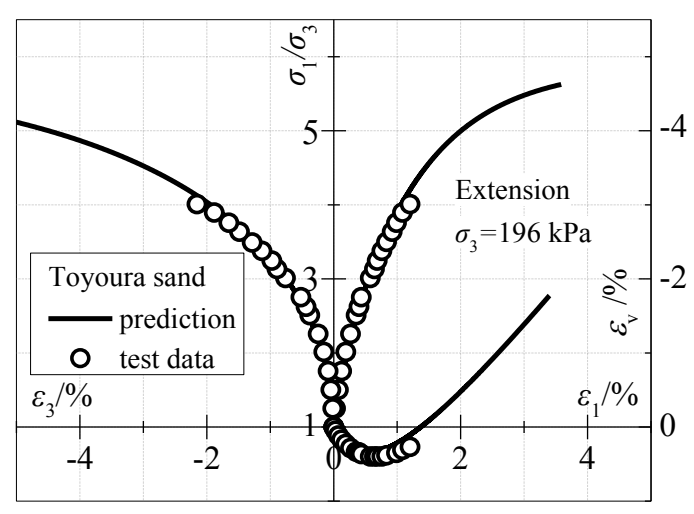

(b) Extension when $\sigma_{3}=p_{0}$

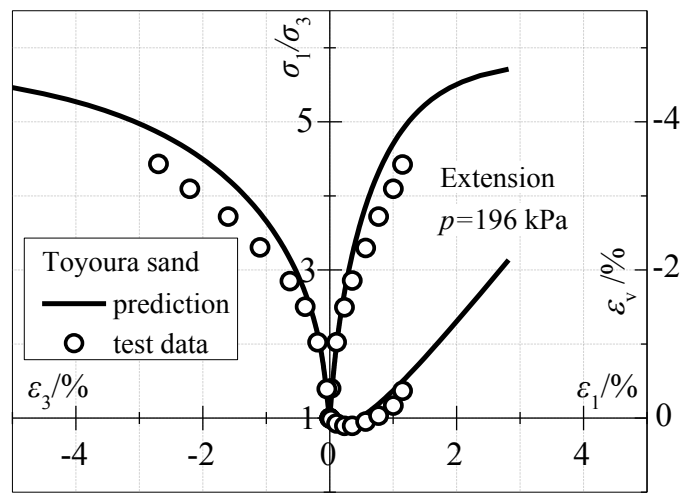

(d) Extension when $p=p_{0}$ 


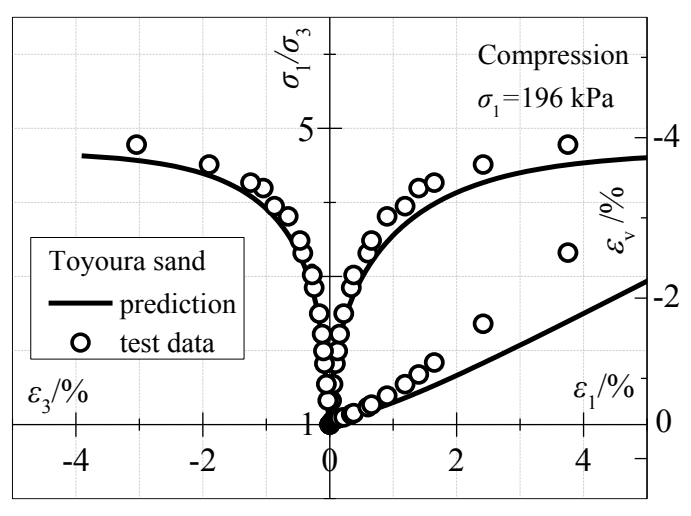

(e) Compression when $\sigma_{1}=p_{0}$

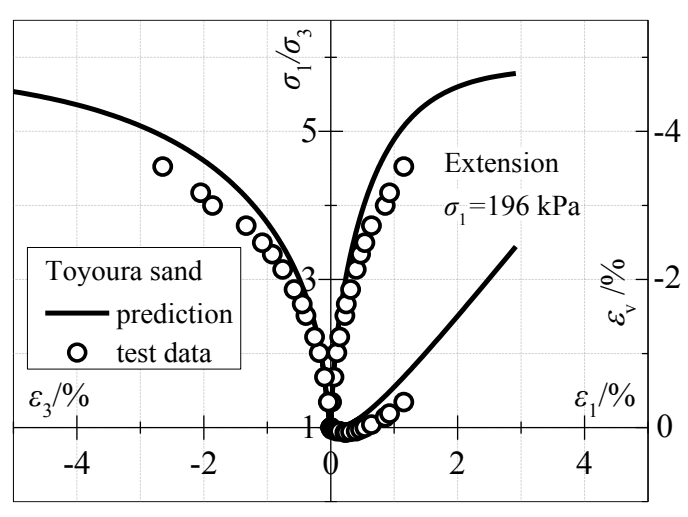

(f) Extension when $\sigma_{1}=p_{0}$

Fig. 11 Comparison between predicted and test results under conventional triaxial conditions.

\subsubsection{Toyoura sand under true triaxial conditions}

True triaxial drained tests under constant mean principal stress $p=196 \mathrm{kPa}{ }^{[29]}$ can be used to demonstrate the capability of the $3 \mathrm{D}$ elastoplastic models for sand ${ }^{[29,41]}$. The values of $\theta$ are $15^{\circ}$, $30^{\circ}$ and $45^{\circ}$, respectively. Triaxial tests under $p=196$ when $\theta=0^{\circ}$ (triaxial compression) and $60^{\circ}$ (triaxial extension) have been used to verify the proposed non-orthogonal model, as shown in Fig. 11(c) and (d). The capability of the proposed model in capturing the behaviour of sand under 3D stress conditions can be verified by the predicting test results of sand, as shown in Fig. 12(a)-(c). The comparisons are arrange in terms of the relation among the principal stress ratio $\sigma_{1} / \sigma_{3}$, volumetric strain $\varepsilon_{\mathrm{v}}$, and principal strains $\varepsilon_{i}(i=1,2,3)$. In addition to well capture the volume change from negative to positive under 3D stress conditions, it is also critical for a 3D model for sand to reflect three-dimensional strength behaviour and the three-dimensional plastic flow direction. For the strength property of sand under $3 \mathrm{D}$ stress conditions $\left(\theta=0^{\circ}, 15^{\circ}, 35^{\circ}, 45^{\circ}\right.$ and $\left.60^{\circ}\right)$, predictions are in good agreement with the experiment results. Moreover, an appropriate description of the plastic flow direction in the deviatoric plane, as illustrated in Section 3.1, provides the proposed model with the ability to capture the relative relationship between different principal strains, as shown in Fig. 12(a)-(c). 


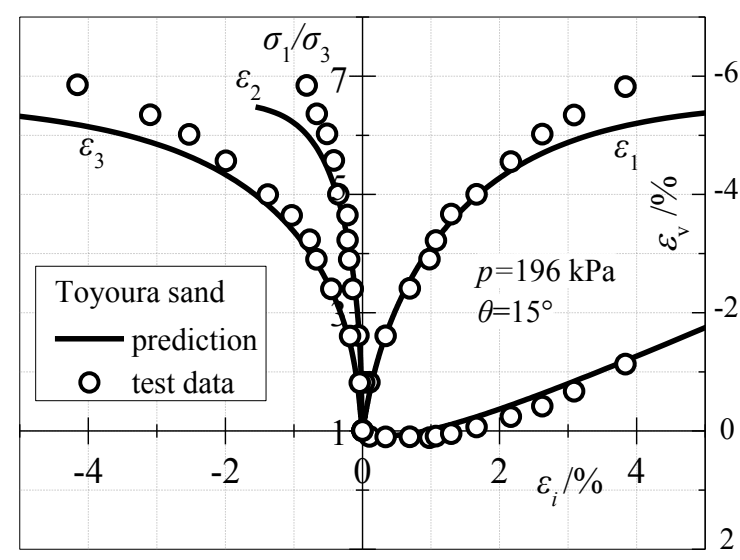

(a) $\theta=15^{\circ}$

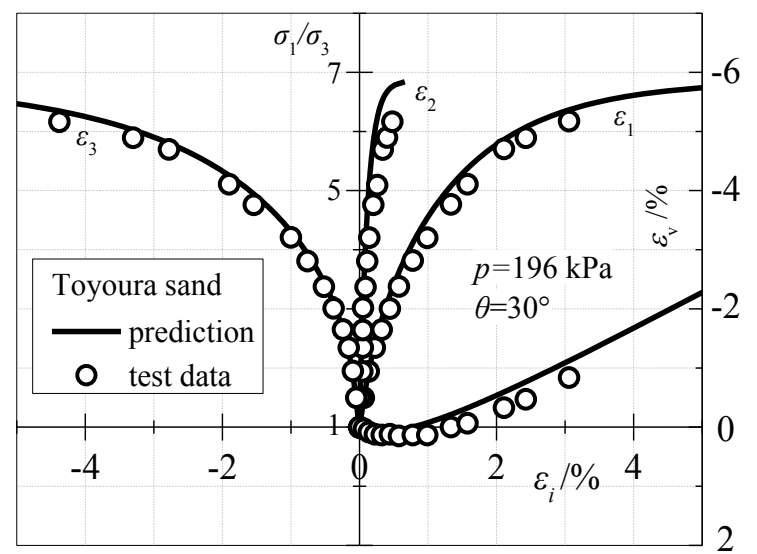

(b) $\theta=30^{\circ}$

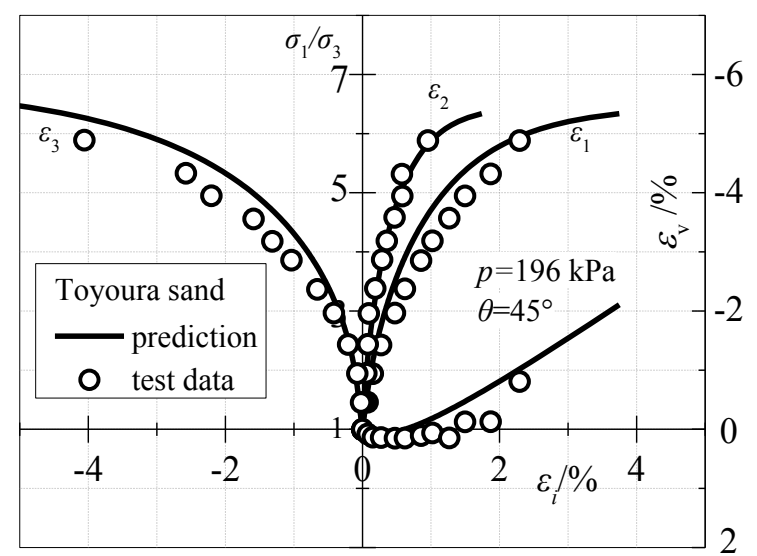

(c) $\theta=45^{\circ}$

Fig. 12 Comparison between predicted and test results under true traixial conditions when $p=p_{0}$.

\section{Conclusions}

In this paper, a non-orthogonal elastoplastic model was proposed within the framework of the non-orthogonal elastoplastic model. Dilatancy behaviours of sand from initial negative to subsequent positive along different stress paths were well described. Only seven material parameters with clear physical meanings are needed and can be easily determined by conventional triaxial tests. 
Model performance and comparison with test results of sand show that the proposed model is capable of capturing the salient behaviour of sand under $3 \mathrm{D}$ stress conditions. The key characteristics are listed as follows:

1. The framework of the 3D non-orthogonal elastoplastic model was established by introducing the characteristic stress, which makes the developed model be born with the potential to capture 3D mechanical behaviour of soil.

2. The plastic flow direction for describing the dilatancy of sand was determined by the nonorthogonal plastic flow rule. Moreover, the complementarity between the non-orthogonal plastic flow rule and the characteristic stress in capturing the 3D plastic flow direction of sand was illustrated.

3. A hardening parameter was newly constructed for capturing the negative and positive dilatancy of sand during the shearing process, which is coordinated with the non-orthogonal plastic flow direction. In addition, its independency from the stress path was demonstrated.

\section{Acknowledgements}

This study was supported by the National Key Research and Development Program of China (Grant No. 2018YFC1504301), National Natural Science Foundation of China (Grant Nos. 51778026, 51421005 and U1839201), and the China Scholar Council. The European Commission for the support to the projects FRAMED "Fracture Across Scales and Materials, Processes and Disciplines" (Grant No. 734485), and HERCULES “Towards geohazards resilient infrastructure under changing climates" (Grant No. 778360) are gratefully acknowledged.

\section{Appendix A Characteristic stress}

The characteristic stress concept was proposed to establish a unified strength criterion (simplified as $\beta$ criterion) in a simple way ${ }^{[40]}$, and has been applied to develop $3 \mathrm{D}$ elastoplastic model for soil ${ }^{[19]}$. The expression of the characteristic stress tensor can be written as:

$$
c_{i j}=p_{r}\left\lfloor\left(\frac{\sigma_{1}}{p_{r}}\right)^{\beta} n_{i}^{(1)} n_{j}^{(1)}+\left(\frac{\sigma_{2}}{p_{r}}\right)^{\beta} n_{i}^{(2)} n_{j}^{(2)}+\left(\frac{\sigma_{3}}{p_{r}}\right)^{\beta} n_{i}^{(3)} n_{j}^{(3)}\right\rfloor
$$

where $c_{i j}$ is the characteristic stress tensor whose principal directions coincide with those of the ordinary stress tensor $\sigma_{i j}$. And the expression of the characteristic principal stress $c_{k}=p_{\mathrm{r}}\left(\sigma_{k} / p_{\mathrm{r}}\right)^{\beta}$ can be obtained the based on Eq. (38). $\sigma_{k}(k=1,2,3)$ is the principal stress. $p_{\mathrm{r}}$ is the reference stress 
for dimensionless transformation, and $p_{\mathrm{r}}=1 \mathrm{kPa}$ is commonly used. $\beta$ is the characteristic stress index,

472 which is a non-dimensional material parameter that ranges from 0 to $1 . n_{i}^{(k)}$ in Eq. (38) is the 473 corresponding directional cosine of the direction vector $\boldsymbol{e}^{(k)}$ of the principal stress, that is, the principal stress vector can be expressed as $c_{k} \boldsymbol{e}^{(k)}$. Therefore, the spectral decomposition of the characteristic stress tensor can be illustrated by the schematic diagram shown in Fig. 13.

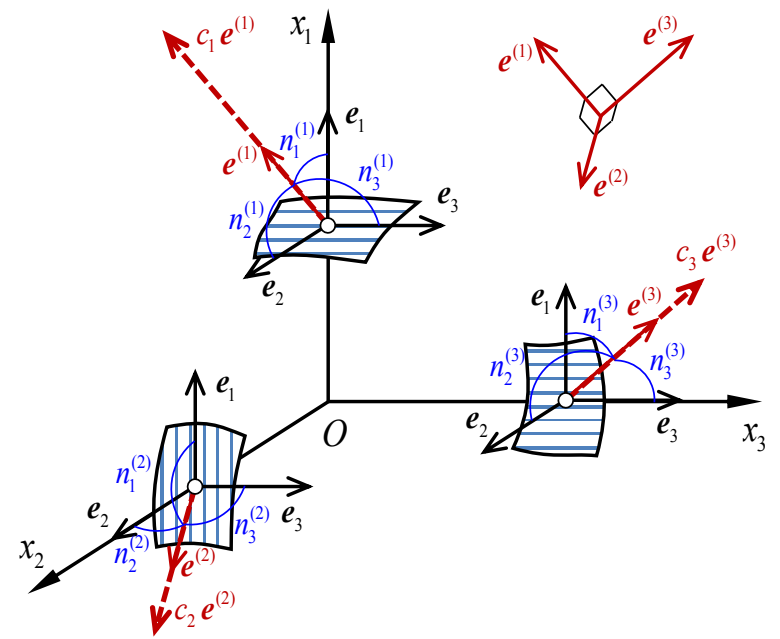

Fig. 13 Spectral decomposition of the characteristic stress tensor.

Based on the friction rule on the octahedral plane under the action of the $c_{i j}$, a nonlinear unified $\beta$ strength criterion ${ }^{[40]}$ was developed, which is used as the failure criterion in this paper:

$$
\frac{c_{\mathrm{s}}}{c_{\mathrm{n}}}=F_{\mathrm{f}}
$$

where $F_{\mathrm{f}}$ is the characteristic failure stress ratio. The specific expressions of the characteristic stress variables and parameters are listed in Tab. A-1, which are also compared with the ordinary stress.

Tab. A-1 Comparison between the ordinary stress and the characteristic stress.

\begin{tabular}{|c|c|c|}
\hline & Ordinary stress & Characteristic stress \\
\hline Stress tensor & $\sigma_{i j}$ & $c_{i j}$ \\
\hline Principal stress & $\sigma_{i}, \quad i=1,2,3$ & $c_{i}=p_{r}\left(\frac{\sigma_{i}}{p_{r}}\right)^{p}, \quad i=1,2,3$ \\
\hline Mean stress & $p=\sigma_{i j} \delta_{i j} / 3$ & $c_{\mathrm{n}}=c_{i j} \delta_{i j} / 3$ \\
\hline General shear stress & $q=\sqrt{\frac{3}{2}\left(\sigma_{i j}-p \delta_{i j}\right)\left(\sigma_{i j}-p \delta_{i j}\right)}$ & $c_{\mathrm{s}}=\sqrt{\frac{3}{2}\left(c_{i j}-c_{\mathrm{n}} \delta_{i j}\right)\left(c_{i j}-c_{\mathrm{n}} \delta_{i j}\right)}$ \\
\hline \multirow{2}{*}{ Stress Lode angle } & $\theta=\arctan$ & \multirow{2}{*}{$\theta_{\beta}=\arctan$} \\
\hline & {$\left[2 \sigma_{1}-\sigma_{2}-\sigma_{3}\right.$} & \\
\hline
\end{tabular}


Stress ratio

Phase transition stress

ratio

Failure stress ratio

$$
\eta=q / p
$$

$\chi=c_{\mathrm{s}} / c_{\mathrm{n}}$

$$
M=\frac{6 \sin \varphi}{3-\sin \varphi} \quad F=3 \frac{(1+\sin \varphi)^{\beta}-(1-\sin \varphi)^{\beta}}{(1+\sin \varphi)^{\beta}+2(1-\sin \varphi)^{\beta}}
$$

$$
M_{\mathrm{f}}=\frac{6 \sin \varphi_{\mathrm{f}}}{3-\sin \varphi_{\mathrm{f}}}
$$

\section{Appendix B Specific expressions of fractional derivative}

The specific expressions of the Caputo fractional derivative of a power function $x^{n}$ is given and expressed as:

$$
{ }_{0} D_{x}^{\mu}\left(x^{n}\right)=\frac{\partial^{\mu}\left(x^{n}\right)}{\partial x^{\mu}}=\frac{\Gamma(n+1) x^{n-\mu}}{\Gamma(n+1-\mu)}
$$

where ${ }_{0} D_{x}^{\mu}$ means the Caputo derivative of order $\mu$. 0 is chosen as the starting point and $x$ is the terminal point in the operator. $\Gamma(\cdot)$ indicates the Gamma function and its expression is $\Gamma(z)=\int_{0}^{\infty} e^{-\tau} \tau^{z-1} \mathrm{~d} \tau$, which satisfies the recursive relation, i.e., $\Gamma(x+1)=x \cdot \Gamma(x)$. In addition, it is worth to note that ${ }_{0} D_{x}^{\mu}(C)=0$, where $C$ is a constant. The linear relationship of the Caputo fractional derivatives is also necessary and can be expressed as:

$$
{ }_{0} D_{x}^{\mu}\left[A_{1} f_{1}(x)+A_{2} f_{2}(x)\right]=A_{1} \cdot{ }_{0} D_{x}^{\mu} f_{1}(x)+A_{2} \cdot{ }_{0} D_{x}^{\mu} f_{2}(x)
$$

\section{References}

[1] Ahadi A, Krenk S. Characteristic state plasticity for granular materials Part II: Model calibration and results. Int J Solids Struct 2000; 37(43):6361-6380.

[2] Pestana JM, Whittle AJ, Salvati LA. Evaluation of a constitutive model for clays and sands: Part I sand behaviour. Int J Numer Anal Met 2002; 26(11):1097-1121.

[3] $\mathrm{Wu} \mathrm{W}$, Bauer E. A simple hypoplastic constitutive model for sand. Int J Numer Anal Met 1994; 18:833-862.

[4] Kruyt NP, Rothenburg L. A micromechanical study of dilatancy of granular materials. J Mech Phys Solids 2016; 95:411-427.

[5] Li XS, Dafalias YF. Dilatancy for cohesionless soils. Géotechnique 2000; 50(4):449-460.

[6] Wan RG, Guo PJ. A simple constitutive model for granular soils: modified stress-dilatancy approach. Comput Geotech 1998; 22(2):109-133.

[7] Yang ZX, Xu TT, Li XS. J2-deformation type model coupled with state dependent dilatancy. Comput Geotech 2019; 105:129-141.

[8] Yao YP, Sun DA, Matsuoka H. A unified constitutive model for both clay and sand with hardening parameter independent on stress path. Comput Geotech 2008; 35(2):210-222.

[9] Wan R, Nicot F, Darve F. Micromechanical formulation of stress dilatancy as a flow rule in plasticity 
of granular materials. J Eng Mech 2010; 136(5):589-598.

[10] Lade PV, Nelson RB, Ito YM. Nonassociated flow and stability of granular materials. J Eng Mech 1987; 113(9):1302-1318.

[11] Collins IF. Associated and non-associated aspects of the constitutive laws for coupled elastic/plastic materials. Int J Geomech 2002; 2(2):259-267.

[12] Collins IF, Houlsby GT. Application of thermomechanical principles to the modelling of geotechnical materials. Proceedings of the Royal Society A: Mathematical, Physical and Engineering Sciences 1997; 453(1964):1975-2001.

[13] Mo PQ, Yu HS. Undrained cavity expansion analysis with a unified state parameter model for clay and sand. Géotechnique 2017; 67(6):503-515.

[14] Salim W, Indraratna B. A new elastoplastic constitutive model for coarse granular aggregates incorporating particle breakage. Can Geotech J 2004; 41(4):657-671.

[15] Desai CS. A general basis for yield, failure and potential functions in plasticity. Int J Numer Anal Met 1980; 4(4):361-375.

[16] Kim MK, Lade PV. Single hardening constitutive model for frictional materials: I. Plastic potential Function. Comput Geotech 1988; 5(4):307-324.

[17] Krenk S. Characteristic state plasticity for granular materials Part I: Basic theory. Int J Solids Struct 2000; 37(43):6343-6360.

[18] Sumelka W. Fractional viscoplasticity. Mech Res Commun 2014; 56:31-36.

[19] Lu DC, Liang JY, Du XL, Ma C, Gao ZW. Fractional elastoplastic constitutive model for soils based on a novel 3D fractional plastic flow rule. Comput Geotech 2019; 105:277-290.

[20] Sun YF, Xiao Y. Fractional order plasticity model for granular soils subjected to monotonic triaxial compression. Int J Solids Struct 2017; 118-119:224-234.

[21] Liang JY, Lu DC, Zhou X, Du XL, Wu W. Non-orthogonal elastoplastic constitutive model with the critical state for clay. Comput Geotech 2019; 116:103200.

[22] Qu PF, Zhu QZ, Sun YF. Elastoplastic modelling of mechanical behavior of rocks with fractionalorder plastic flow. Int J Mech Sci 2019; 163(4.134):105102.

[23] Sun YF, Gao YF, Shen Y. Mathematical aspect of the state-dependent stress-dilatancy of granular soil under triaxial loading. Géotechnique 2018; 69(2):158-165.

[24] Matsuoka H, Yao YP, Sun D. The Cam-clay models revised by the SMP criterion. Soils Found 1999; 39(1):81-95.

[25] Roscoe KH, Burland JB. On the generalised stress-strain behaviour of 'wet' clay. Engineering Plasticity 1968:535-609.

[26] Borja RI, Lee SR. Cam-Clay plasticity, Part I: Implicit integration of elasto-plastic constitutive relations. Comput Method Appl M 1990; 78:49-72.

[27] Xiao Y, Liu HL, Chen YM, Jiang JS. Bounding surface model for rockfill materials dependent on density and pressure under triaxial stress conditions. J Eng Mech 2014; 140(4):4014002.

[28] Been K, Jefferies MG, Hachey J. The critical state of sands. Géotechnique 1991; 41(3):365-381.

[29] Nakai T. An isotropic hardening elastoplastic model for sand considering the stress path dependency in three-dimensional stresses. Soils Found 1989; 29(1):119-137.

[30] Yu HS. CASM: A unified state parameter model for clay and sand. Int J Numer Anal Met 1998; 22(8):621-653.

[31] Li XS, Dafalias YF. Constitutive Modeling of Inherently Anisotropic Sand Behavior. J Geotech Geoenviron 2002; 128(10):868-880. 
[32] Sun DA, Matsuoka H, Yao YP, Ishii H. An anisotropic hardening elastoplastic model for clays and sands and its application to FE analysis. Comput Geotech 2004; 31(1):37-46.

[33] Chen SL, Liu K. Undrained cylindrical cavity expansion in anisotropic critical state soils. Géotechnique 2019; 69(3):189-202.

[34] Gao ZW, Zhao JD, Li XS, Dafalias YF. A critical state sand plasticity model accounting for fabric evolution. Int J Numer Anal Met 2014; 38(4):370-390.

[35] Petalas AL, Dafalias YF, Papadimitriou AG. SANISAND-FN: An evolving fabric-based sand model accounting for stress principal axes rotation. Int J Numer Anal Met 2018; 43(1):97-123.

[36] Papadimitriou AG, Chaloulos YK, Dafalias YF. A fabric-based sand plasticity model with reversal surfaces within anisotropic critical state theory. Acta Geotech 2019; 14(2):253-277.

[37] Lu DC, Zhou X, Du XL, Wang GS. A 3D fractional elastoplastic constitutive model for concrete material. Int J Solids Struct 2019; 165:160-175.

[38] Cui WJ, Potts DM, Zdravković L, Gawecka KA, Taborda DMG. An alternative coupled thermohydro-mechanical finite element formulation for fully saturated soils. Comput Geotech 2018; 94:2230.

[39] Sumelka W, Nowak M. Non-normality and induced plastic anisotropy under fractional plastic flow rule: a numerical study. Int J Numer Anal Met 2016; 40(5):651-675.

[40] Lu DC, Ma C, Du XL, Jin L, Gong QM. Development of a new nonlinear unified strength theory for geomaterials based on the characteristic stress concept. Int J Geomech 2017; 17(2):4016058.

[41] Yao YP, Liu L, Luo T, Tian Y, Zhang JM. Unified hardening (UH) model for clays and sands. Comput Geotech 2019; 110:326-343. 